\title{
Editorial: Addressing Cardiovascular Disease Globally for Near-Term Impact: Yes We Can
}

\author{
Moïse Desvarieux, $\mathrm{MD}, \mathrm{PhD},{ }^{1,2,3}$ \\ Fred Paccaud, MD, MSc ${ }^{4,5}$
}

Suggested Citation: Desvarieux M, Paccaud F. Addressing cardiovascular disease globally for near-term impact: yes we can. Public Health Reviews. 2012;33:346-50.

The $20^{\text {th }}$ century is likely to be remembered as a period during which a rise and fall of cardiovascular disease was experienced in North America and Western Europe. In most of the countries in these regions, the incidence of stroke and, then, of ischemic heart disease increased slowly but steadily from the beginning of the $20^{\text {th }}$ century, then reached a peak in the sixties or seventies, and eventually started to decrease. In almost all Western European countries, the incidence rates are currently still declining, with a shift of cardiovascular deaths towards higher age. Thus, the absolute number of cases tends to remain constant (or even to increase) because of the counteracting effect of population ageing.

In the early 1970s, Abdul Omran offered the clever paradigm of epidemiological transition to describe the intricate changes of demography, socioeconomic environment, lifestyles and health services leading to the predominance of chronic and degenerative diseases. ${ }^{1}$ Although not fully illuminating the causal pathways explaining the epidemiological changes of cardiovascular disease, Omran's paradigm foresaw what sorts of challenges would predominate in the future. In other words, the paradigm

\footnotetext{
${ }^{1}$ Department of Epidemiology, Columbia University Mailman School of Public Health, New York.

${ }^{2}$ Institut National de la Santé et de la Recherche Médicale (INSERM), U 738.

${ }^{3}$ Ecole des Hautes Études en Santé Publique (EHESP), Paris and Rennes.

${ }^{4}$ Institute for Social and Preventive Medicine, University Hospital Center and Faculty of Biology and Medicine, Lausanne.

${ }^{5}$ Swiss School of Public Health, Zurich.
} 
of epidemiological transition opened up a new area of public health, illustrated by the globalization of cardiovascular disease.

Sadly, it took a long time to fully draw conclusions from Omran's vision in terms of public health priorities and strategies, especially in low and middle income countries. In fact, arguably the first large scale endorsement of health transition at the global level took place only recently in September 2011 at the United Nations High-level Meeting on Non-Communicable Diseases Prevention and Control held in New York, ${ }^{2}$ of which cardiovascular disease is an important part. This was exactly 40 years after the publication of Omran's paper. But the evidence is overwhelming: in 2005, the estimated losses in national income from heart disease, stroke and diabetes (reported in international dollars) were $\$ 18$ billion in China, $\$ 11$ billion in the Russian Federation, $\$ 9$ billion in India and $\$ 3$ billion dollars in Brazil. ${ }^{3}$

However, evidence abounds that prevention of cardiovascular disease can be effective at a population level. In Finland, a community and national intervention aimed at changing behaviors resulted in a reduction of coronary deaths by 85 percent as well as a reduction in all-cause mortality, a feat described with hindsight by Oppenheimer, Blackburn and Puska in this issue. ${ }^{4}$ Importantly, while this reduction was greater in younger age groups ( $-96 \%$ in men $35-44$ years), it remained significant in all ages of the population (-69\% in men 65-79 years), signaling that it is never too late for prevention. In Poland, after the government ended the subsidy on highlysaturated meats and fats and encouraged the consumption of vegetables, coronary heart disease mortality rates fell by 25 percent in the following five years, even without noticeable improvement in the health care system., Further dramatic demonstration of the effect of prevention is provided from the town of Helena in the state of Montana, United States where population acute coronary syndromes decrease by 40 percent in six months after a smoking ban, and returned to previous levels when the law was rescinded. The fruits of prevention are thus already harvested in just months and years, and not simply decades after implementation, a point worth making to populations, public health decision-makers and politicians alike. ${ }^{8}$

Moreover, these effects are demonstrable in populations as disparate as Cuba and the US. The economic crisis of 1991-1995 in Cuba led to increased physical activity from 30 percent to 67 percent (due to fuel shortages for buses), resulting in a decreased prevalence of obesity from 14 percent to seven percent and a fall of coronary deaths within a year and a 39 percent decline by $2002 .{ }^{9}$ In the vastly different US population, with a decidedly distinct health care system, a nationwide analysis demonstrated that primary and secondary prevention still explain a higher proportion of the decline in cardiovascular deaths than advances in medical therapies, 
with 44 percent of the decline attributed to changes in risk factors, despite the increase in the prevalence of obesity..$^{10}$ Therefore, prevention works for all age-groups, in populations as diverse as those found in Cuba, Poland, Finland and the US, and yields near-term results in cardiovascular disease.

This prevention has to be multifaceted. In this issue of the Journal, we have aimed to provide both first-hand accounts of what has worked (Luepker on WHO MONICA ${ }^{11}$; Oppenheimer, Blackburn and Puska on the journey from Framingham to North Karelia ${ }^{4}$ ) as well as a window on new challenges facing our transitioning world (Bovet and Paccaud on low and middle-income countries ${ }^{12}$; Pajak and Kozela on Central and Eastern Europe $^{13}$; Petrukhin and Lunina on Russia ${ }^{14}$ ), while addressing novel concepts (Jacobs, Tapsell and Temple on food synergy ${ }^{15}$ ), approaches (Lovasi, Grady and Rundle on walkability and health ${ }^{16}$ ), controversies (Bochud, et al. on dietary salt intake ${ }^{17}$ ), reasoned regulatory arguments (Jha on avoidable deaths from smoking ${ }^{18}$ ) or pertinent reflections (Bayer and Feldman on the limits of public health achievements for tobacco control ${ }^{19}$; Lang, et al. on social determinants ${ }^{20}$ ) on our path to prevention. Although naturally mentioned throughout, we do not specifically address stroke, which we aim to do in a subsequent relevant issue. We hope that this issue of Public Health Reviews will be helpful to practitioners of public health, researchers and public policy decision-makers alike, as the enclosed articles offer a mix of fundamental issues and practical aspects related to cardiovascular health. Quite fittingly, this issue begins with career reflections from Daan Kromhout ${ }^{21}$ and Salim Yusuf, ${ }^{22}$ two distinguished cardiovascular researchers embodying these efforts from vastly different vantage points yet unified in a common goal, for which we are grateful.

\section{REFERENCES:}

1. Omran AR. The epidemiologic transition. A theory of the epidemiology of population change. Milbank Mem Fund Q. 1971;49:509-38.

2. United Nations high-level meeting on noncommunicable disease prevention and control: NCD summit to shape the international agenda 2011. Available from URL: http://www.who.int/nmh/events/un_ncd_summit2011/en/ (accessed 14 September 2012).

3. World Health Organization. Preventing chronic diseases: a vital investment. Geneva: WHO; 2005.

4. Oppenheimer GM, Blackburn H, Puska P. From Framingham to North Karelia to U.S. Community Prevention Programs: negotiating research agendas for coronary heart disease in the second half of the 20th Century. Public Health Reviews. 2012;33:450-83. 
5. Zatonski WA, Willett W. Changes in dietary fat and declining coronary heart disease in Poland. BMJ. 2005;331:187-8.

6. Zatonski WA, McMichael AJ, Powles JW. Ecological study of reasons for sharp decline in mortality from ischaemic heart disease in Poland since 1991. BMJ. 1998;316:1047-51.

7. Sargent RP, Shepard RM, Glantz SA. Reduced incidence of admissions for myocardial infarction associated with public smoking ban: before and after study. BMJ. 2004;328:977-80.

8. Desvarieux M, Fried L, Galea S, Fairchild A, Levin B, Sparer M, et al., from the Chronic Disease Initiative. Position Paper on United Nations High-Level Meeting on Noncommunicable Disease Prevention and Control. Available from URL: www.mailman.columbia.edu/sites/default/files/Mailman_NCDs. pdf (accessed 5 September 2012).

9. Franco M, Ordunez P, Caballero B, Tapia Granado JA, Bernal JL, Guallar E, Cooper RS. Impact of energy intake, physical activity and population-wide weight loss on cardiovascular disease and diabetes mortality in Cuba, 19802005. Am J Epidemiol. 2007;166:1374-80.

10. Ford ES, Ajani UA, Croft JB, Critchley JA, Labarthe DR, Thomas E. Kottke TE, et al. Explaining the decrease in U.S. deaths from coronary disease, 1980-2000. N Engl J Med. 2007;356:2388-98.

11. Luepker RV. WHO MONICA Project: what have we learned and where to go from here? Public Health Reviews. 2012;33:373-96.

12. Bovet P, Paccaud F. Cardiovascular disease and the changing face of global public health: a focus on low and middle income countries. Public Health Reviews. 2012;33:397-415.

13. Pajak A, Kozela M. Cardiovascular disease in Central and East Europe. Public Health Reviews. 2012;33:416-35.

14. Petrukhin IS, Lunina EY. Cardiovascular Disease Risk Factors and Mortality in Russia: Challenges and Barriers. Public Health Reviews. 2012;33:436-49.

15. Jacobs DR, Tapsell LC, Temple NJ. food synergy: the key to balancing the nutrition effort. Public Health Reviews. 2012;33:507-29.

16. Lovasi GS, Grady S, Rundle A. Steps forward: review and recommendations for research on walkability, physical activity and cardiovascular health. Public Health Reviews. 2012;33:484-506.

17. Bochud M, Marques-Vidal P, Burnier M, Paccaud F. Dietary salt intake and cardiovascular disease: summarizing the evidence. Public Health Reviews. 2012;33:530-52.

18. Jha P. Avoidable deaths from smoking: a global perspective. Public Health Reviews. 2012;33:569-600.

19. Bayer R, Feldman E. Tobacco control in industrialized nations: the limits of public health achievement. Public Health Reviews. 2012;33:553-68.

20. Lang T, Lepage B, Schieber A-C, Kelly-Irving M. Social determinants of cardiovascular diseases. Public Health Reviews. 2012;33:601-22. 
21. Kromhout D. Preface: a career in nutrition and cardiovascular disease: from research to results to public health policy. Public Health Reviews. 2012; 33:351-62.

22. Yusuf S. Preface: reflections on a career in health research, international collaboration and mentoring. Public Health Reviews. 2012;33:363-72. 